\title{
Degradation Study of LLDPE-starch-clay Composite Film Using Xenon Arc and Characterized on Mechanical and Chemical Properties
}

\author{
Jayatin ${ }^{*}$, Chandra Liza, Syuhada \\ Center for Polymer Technology, Agency for Assessment and Application of Technology, Indonesia
}

Copyright $(2018$ by authors, all rights reserved. Authors agree that this article remains permanently open access under the terms of the Creative Commons Attribution License 4.0 International License

\begin{abstract}
Starch blending with linear low-density polyethylene (LLDPE) is one of the plastic packaging materials alternative used for solving the plastic waste problem that difficult to degrade. Polymeric materials will change when exposed to weather that releases heat, chemistry, and light. It can be a trigger factor in the degradation process. Xenon Arc accelerated weather simulation test is one way to find out the resistance of plastic materials to weather. This study aimed to explain the effect of xenon arc light on LLDPE-starch-clay composite. In this work accelerated photodegradation tests using Xenon Arc ATLAS Ci 3000+ were carried out on LLDPE-starch-clay composite sample films. Clay, compatibilizers, and starch with a starch content of $10 \mathrm{wt} \%$ and $20 \mathrm{wt} \%$ were used to make composites masterbatch. The composite masterbatch then extruded with LLDPE and was prepared to make a film sample using Rheomex Haake Blown film. Mechanical properties of the film samples before and after xenon arc accelerated photodegradation treatment were tested using Universal Testing Machine (UTM) Shimadzu AGS-10kNG. The composite sample made from ten $\mathrm{wt} \%$ starch showed $55 \%$ reduction in tensile strength after 14 days of degradation while sample prepared with $20 \mathrm{wt} \%$ starches was brittle after seven days of exposure to xenon arc light. Fourier Transform Infra-Red (FTIR) spectrophotometer test result for composite samples made from $10 \mathrm{wt} \%$ and $20 \mathrm{wt} \%$ starch after exposure to xenon arc light show increasing the intensity at the wave number of $1722 \mathrm{~cm}-1$ that corresponding to carbonyl bond this proved that degradation has occurred.
\end{abstract}

Keywords Photodegradation, Mechanical, Chemical, Starch, LLDPE, Clay, Composite

\section{Introduction}

Plastics are used widely in our daily life and mostly used as packaging. Application of plastic materials for packaging is becoming the largest source of plastics waste. Plastics are difficult to degrade naturally, so this will increase environmental problems. This waste compared to others has the lowest number of material that can be reused [1]. Research and development of plastic packaging that is degraded rapidly in the environment driven by increasing awareness of the environmental impact of plastic waste, especially packaging [2]. Plenty of concepts to control the lifetime of plastics such as blending synthetic polymers with biopolymers and chemical or physical modification of the composite polymer have been recommended [4].

Photodegradation (including photo-oxidation and weathering, the combined action of sunlight, air, rain, and pollutants), biodegradation, auto-oxidation, and hydrolysis might cause degradation of organic matter. UV photons of sunlight are quite energetic to break some bonds directly and to initiate the breaking of molecules through photooxidation, so its essential for the degradation of organic material [5]. The effect of sunlight on the polymer material would lead to a series of reactions such as photolytic, photo-oxidative, and thermo-oxidative, which might lead to degradation of materials through chemical degradation resulting in brittleness, brightness loss, discoloration, blur and the formation of surface cracks [6]. Carbonyl index analysis can be used to identified photodegradation. Any change in the carbonyl index showed that photodegradation occurred. [7]. During photodegradation besides the reduction in molecular weight, also the formation of chemical groups like carbonyl, carboxylic acids and hydroperoxides [6]. Weathering test involves the effect of photophysical and photochemical from ultraviolet radiation (UV) photons, the atmospheric oxidative of oxygen and the hydrolytic of water. Weathering test to organic matter might affect severely [5].

This work investigated the photodegradation of LLDPE-starch-clay composites with some starch content at different exposure times. The aim is to know the effect of xenon arc light on the composites. 


\section{Materials and Methods}

\subsection{Materials}

Organo layer silicate (OLS) cloisite 20A used was from Southern Clay Inc., USA, that already treated with glycerol monostearate (GMS). Glycerol monostearate provided by the anonymous local company. Polyethylene graft maleic anhydride (PE-g-MA) viscosity $1.700-4.500 \mathrm{cP}\left(140^{\circ} \mathrm{C}\right)$ from Sigma Aldrich applied as a compatibilizer and cassava starch from the commercial market used as the biodegradable material. Antioxidant Irganox 205 was utilized to prevent LLDPE and starch degradation in the extrusion process.

\subsection{Preparation and Characterization}

The composite compound of LLDPE-starch with treated OLS was carried out by melt compounding method using Collin twin screw extruder. The processing condition of twin screw extruder was at a temperature range from $40-175 \mathrm{oC}$ and screw speed $20 \mathrm{rpm}$. Masterbatch in this compound was OLS treated with GMS, blended with $35 \mathrm{wt} \%$ starch. The composition of the composite compound LLDPE-Starch-clay was shown in table 1. All of the materials dried, before the extrusion process.

Table 1. The Composition of The Composite Compound LLDPE-Starch-clay

\begin{tabular}{|c|c|c|c|}
\hline Nomenclature & $\begin{array}{c}\text { LLDPE } \\
(\mathrm{phr})\end{array}$ & $\begin{array}{c}\text { Masterbatch } \\
(\mathrm{phr})\end{array}$ & $\begin{array}{c}\text { Antioxidant } \\
(\mathrm{phr})\end{array}$ \\
\hline $\begin{array}{c}\text { Compound 10 } \\
\mathrm{wt} \% \text { Starch }\end{array}$ & 87.8 & 12 & 0.2 \\
\hline $\begin{array}{c}\text { Compound } 20 \\
\mathrm{wt} \% \text { Starch }\end{array}$ & 75.8 & 24 & 0.2 \\
\hline
\end{tabular}

Packaging prototype was made from the compound using Rheomex Blown Film - Haake with processing condition at a temperature range $40-190 \mathrm{oC}$ and screw speed $40 \mathrm{rpm}$. Compounds before processing were dried in the vacuum oven at temperature $50 \mathrm{oC}$ for 24 hours. Photodegradation study was carried out using Xenon Arc Ci 3000 for 14 days at operation condition as follow:

Table 2., Operating Condition Xenon Arc Ci 3000 for Photodegradation Characterization

\begin{tabular}{|c|c|c|}
\hline Condition & Dark & Light \\
\hline Irradiant & --- & $0.55 \pm 0.01 \mathrm{~W} / \mathrm{m}^{2} @ 340 \mathrm{~nm}$ \\
\hline BPT & $38 \pm 2^{\circ} \mathrm{C}$ & $89 \pm 3^{\circ} \mathrm{C}$ \\
\hline Dry Bulb Condition & $38 \pm 2^{\circ} \mathrm{C}$ & $62 \pm 2^{\circ} \mathrm{C}$ \\
\hline RH & $95 \pm 5 \%$ & $50 \pm 5 \%$ \\
\hline Conditioning water & $40 \pm 4^{\circ} \mathrm{C}$ & $60 \pm 4^{\circ} \mathrm{C}$ \\
\hline Duration & $1,0 \mathrm{hr}$ & $3,8 \mathrm{hrs}$ \\
\hline
\end{tabular}

Samples were taken out from Xenon after three days, seven days and 14 days, then used for mechanical properties characterization based on ISO 527-3 standard using Universal Testing Machine (UTM) Shimadzu AGS-10kNg. Tensile test held at temperature $22,6^{\circ} \mathrm{C}$, RH $51 \%$, pretension $0,01 \mathrm{~N}$, grip length $70 \mathrm{~mm}$, and test speed $50 \mathrm{~mm} / \mathrm{min}$. FTIR test using FTIR Shimadzu at wavelength $4000-400 \mathrm{~cm}^{-1}$ was done with thin film transmission method for functional group identification to know the degradation process of the samples.

\section{Results and Discussion}

Photodegradation study was done using Xenon arc accelerated weathering. The Xenon arc condition (table 2) applied in this study was used as a simulation for outdoor application. Mechanical and FTIR test was done to characterize the photodegradation effect on the sample.

\subsection{Effect Xenon Arc Treatment on Mechanical Properties}

Xenon arc treatment on composite produced a different effect on the mechanical properties of the composite with different starch content. Fig. 1 shows the tensile strength graph before and after photodegradation of the composite without starch, with $10 \mathrm{wt} \%$ starch and with $20 \mathrm{wt} \%$ starch. The figure showed that the mechanical properties of the composite with $20 \mathrm{wt} \%$ starch decreased significantly after seven days of treatment with xenon arc. On composite prepared with $10 \mathrm{wt} \%$ starch and without starch, the tensile strength properties were still quite good until 14 days treatment with xenon. The tensile strength of the composite prepared with $10 \mathrm{wt} \%$ starch decreased $55 \%$ after 14 days treatment with xenon arc and for the composite made by 20 wt $\%$ starch was already brittle after seven days. Meanwhile, pure LLDPE used as a control was decreased by $30 \%$ in tensile strength after 14 days.

Photodegradation effects by Xenon arc treatment on the strain at break of the composite prepared without starch, 10 $w t \%$ starch, and $20 \mathrm{wt} \%$ starch shown in Fig. 2. The graph showed that strain at break of the composite made from 10 $\mathrm{wt} \%$, and $20 \mathrm{wt} \%$ starches are decreased significantly after three days. This confirmed that composites prepared with $10 \mathrm{wt} \%$ and $20 \mathrm{wt} \%$ starches after treated with xenon arc for three days had become a brittle condition. On the other hand composites without starch, strain at break was still good until 14 days. This result shows that the starch content had more susceptible effect in Xenon Arc accelerated weathering test. Xenon Arc treatment could lead to photodegradation on the sample, mostly on starch portion. Photodegradation would change the molecular structure of polymers, especially on the carbonyl $(-\mathrm{C}=\mathrm{O})$ group, and vinyl $(-\mathrm{CH}=\mathrm{CH}-)$ group $[6,7]$. 


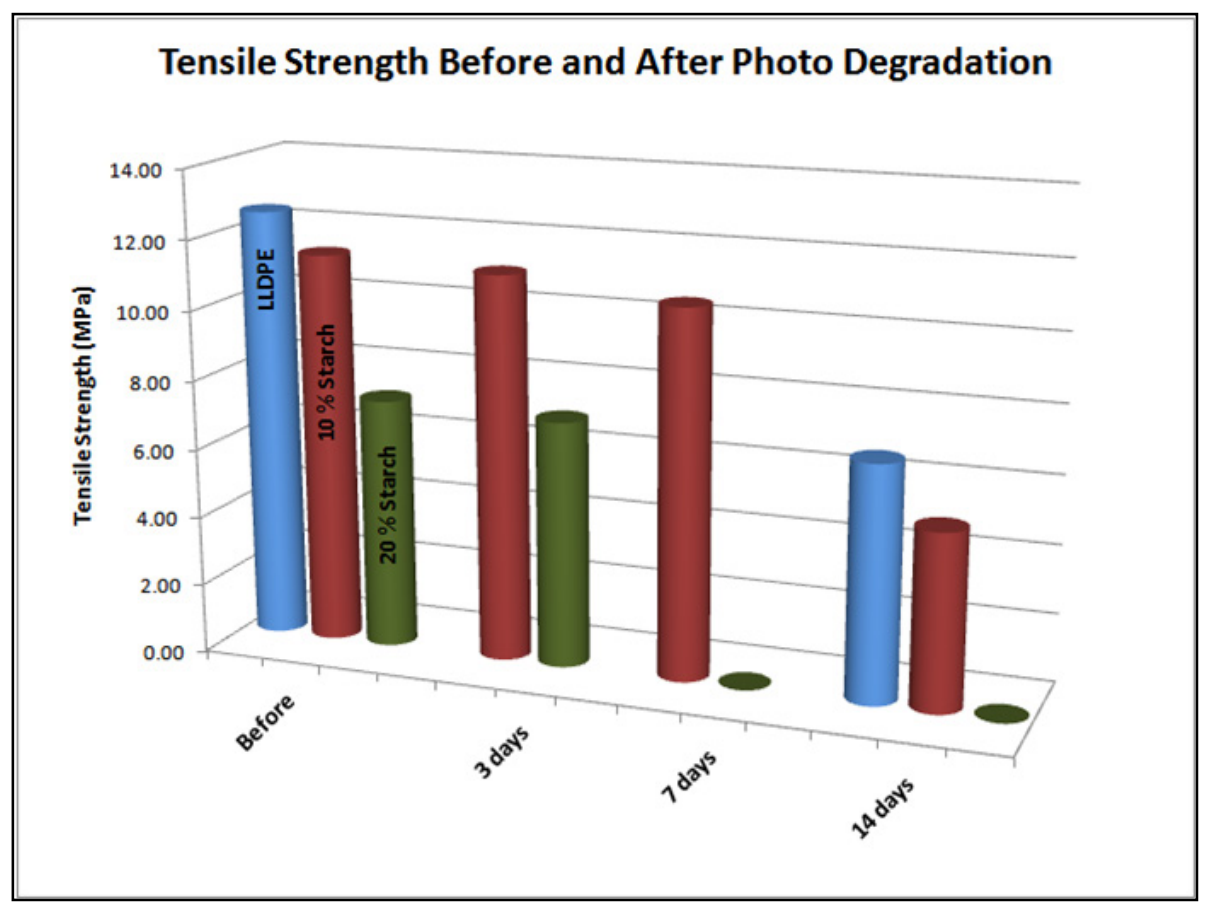

Figure 1. The tensile strength of composite without starch, $10 \mathrm{wt} \%$ starch, and $20 \mathrm{wt} \%$ starch tested before and after Xenon Arc accelerated weathering.

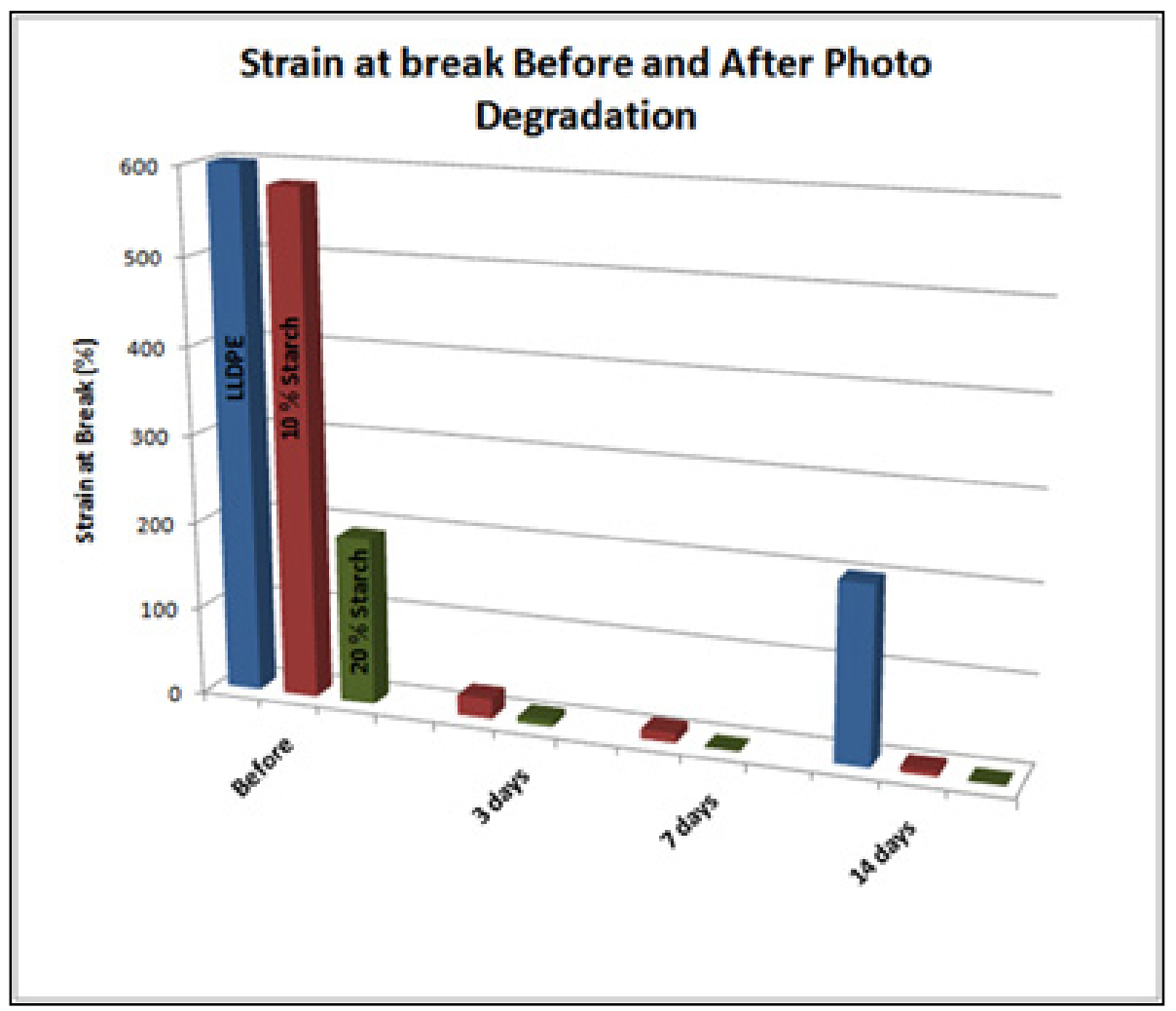

Figure2. Strain at break of composite without starch, $10 \mathrm{wt} \%$ starch, and $20 \mathrm{wt} \%$ starch before and after Xenon Arc accelerated weathering test

\subsection{The Effect of Xenon Arc Treatment on Chemical Structure}

FTIR used to analyze chemical structure changes after the Xenon Arc treatment. FTIR spectra for the composites prepared without starch, with $10 \mathrm{wt} \%$ starch, and with $20 \mathrm{wt} \%$ starch before and after Xenon Arc accelerated weathering test showed in Fig. 3, 4, and 5.

Figure 4 and 5 showed increasing the intensity of carbonyl bond at the wavenumber $1722 \mathrm{~cm}-1$ for the composite with $10 \mathrm{wt} \%$ and $20 \mathrm{wt} \%$ starches after xenon arc treatment. 
Carbonyl bond formation happened during photodegradation, so it proved that degradation has occurred. Carbonyl Index (CI) calculated based on carbonyl band at wave number 1722 $\mathrm{cm}^{-1}$ compared to $\mathrm{CH} 2$ bending at wave number $1460 \mathrm{~cm}^{-1}$ as a reference, according to the equation:

$$
\mathrm{CI}=\frac{\text { (area of absorbance } 1722 \mathrm{~cm}^{-1} \text { ) }}{\left(\text { area of absorbance } 1460 \mathrm{~cm}^{-1}\right. \text { ) }} \times 100 \%
$$

Figure 6 showed percent carbonyl index of
LLDPE-starch-clay composite after treatment for 14 days using Xenon Arc. The carbonyl index (CI) increased related to irradiation time and starch content. Composite LLDPE-starch-clay prepared with $10 \mathrm{wt} \%$ starch percent carbonyl index increased from $59 \%$ to $95 \%$ after treatment for 14 days, and for the composite made from $20 \mathrm{wt} \%$ starch increased from $74 \%$ to $99,4 \%$. These data confirmed that degradation occurred through carbonyl index formation resulting from the broken chain caused by photodegradation.

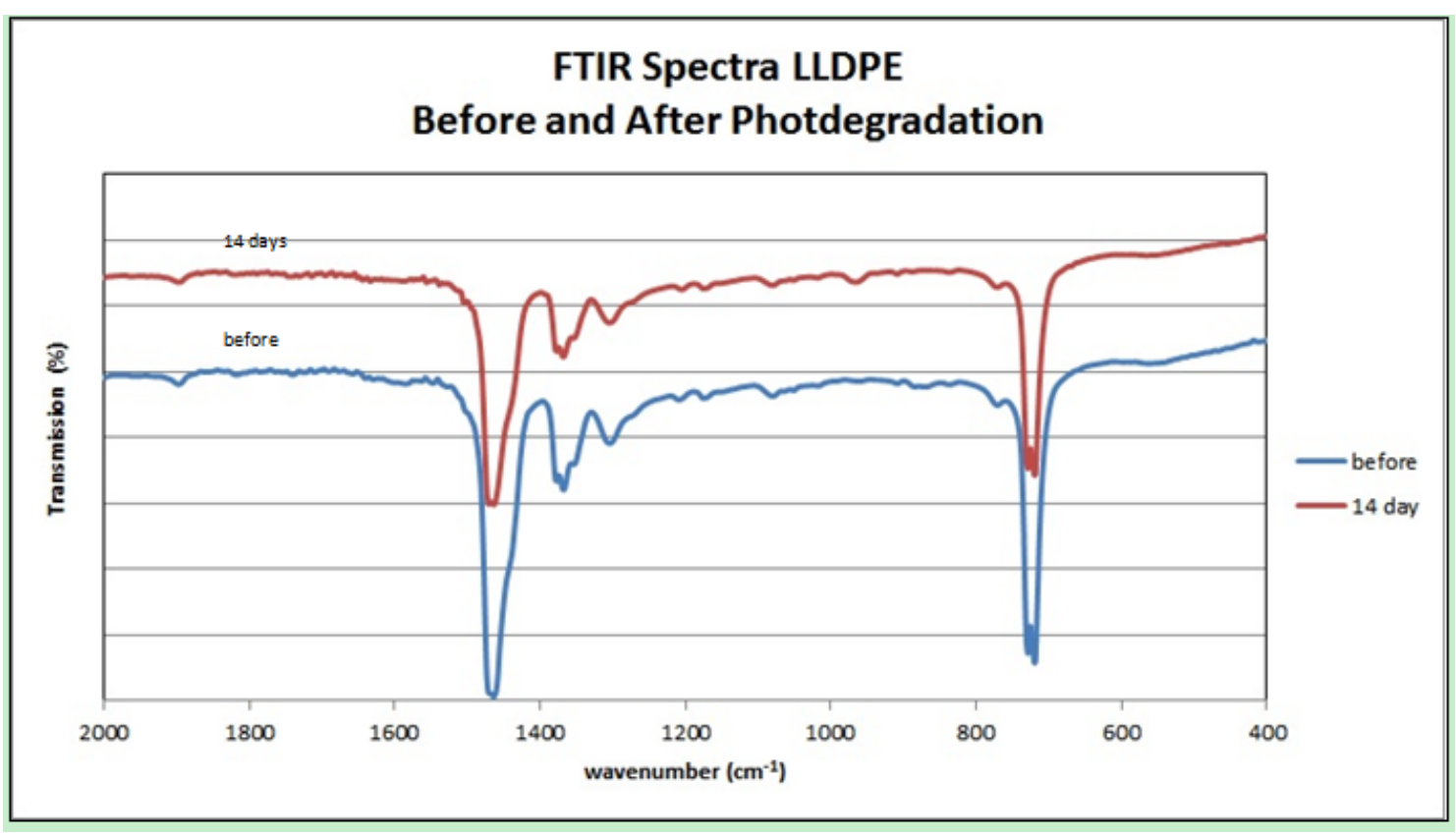

Figure 3. FTIR spectra of composite without starch before and after photodegradation

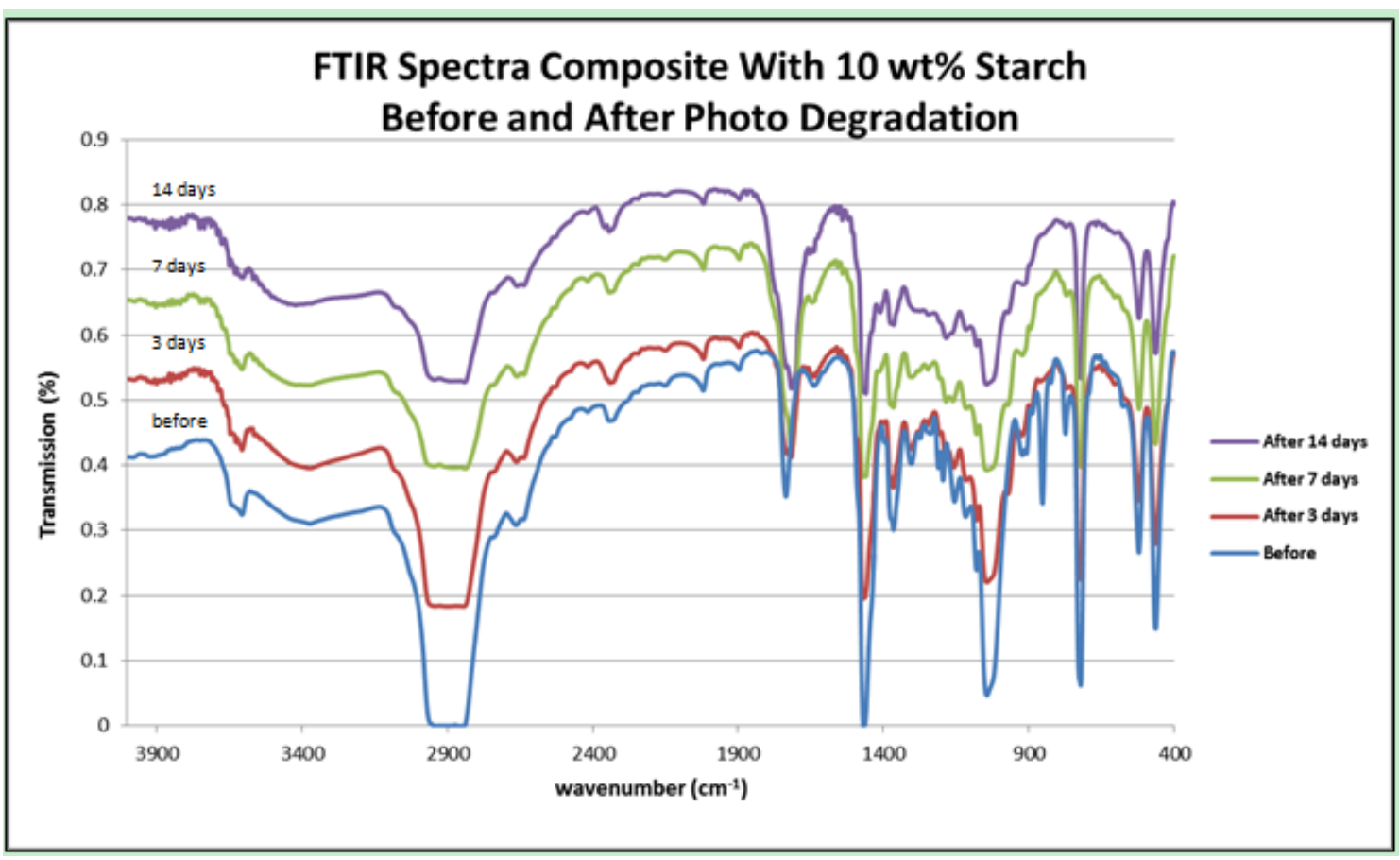

Figure 4. FTIR spectra of the composite with $10 \mathrm{wt} \%$ starch before and after photodegradation 


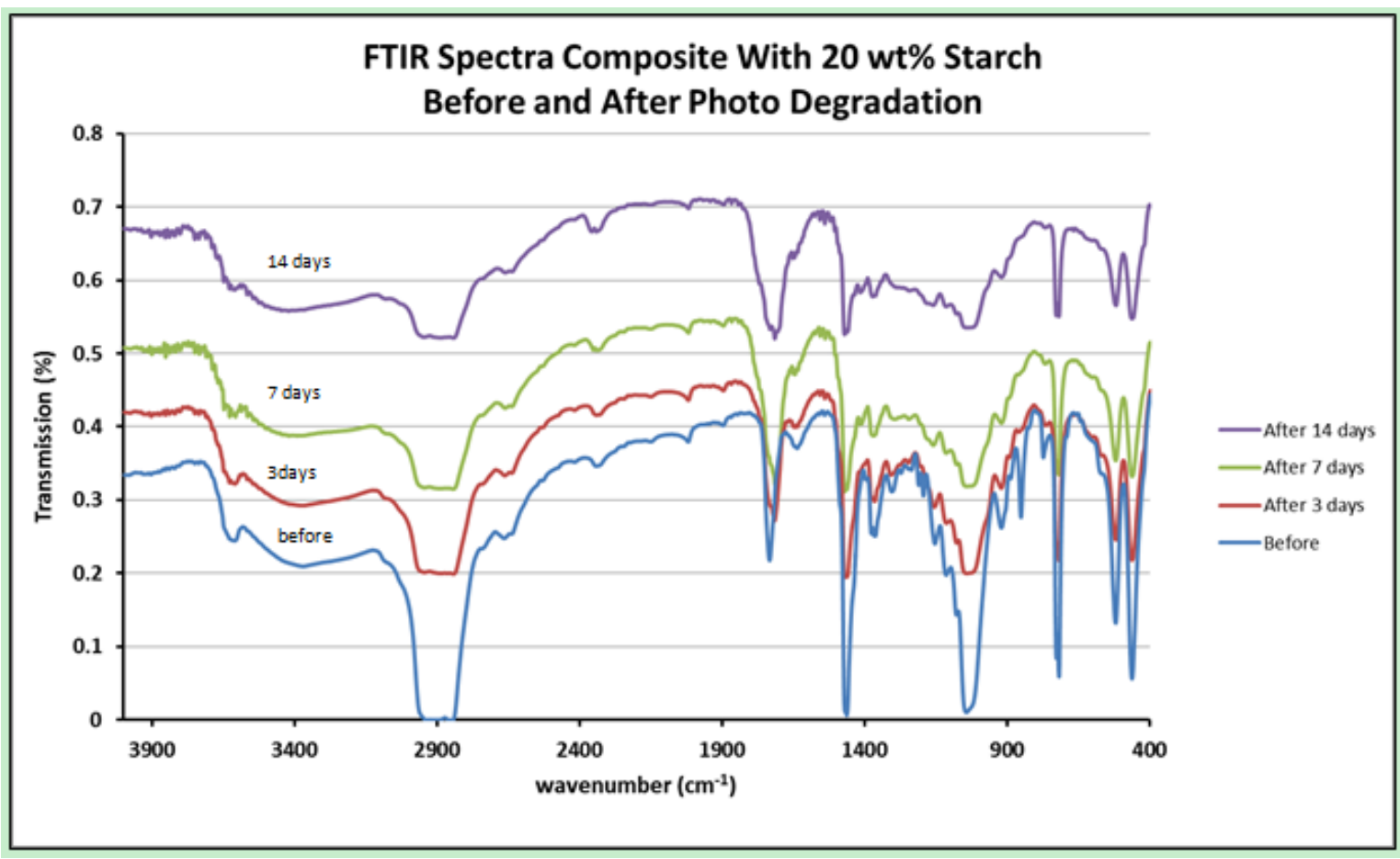

Figure 5. FTIR spectra of the composite with $20 \mathrm{wt} \%$ starch before and after photodegradation

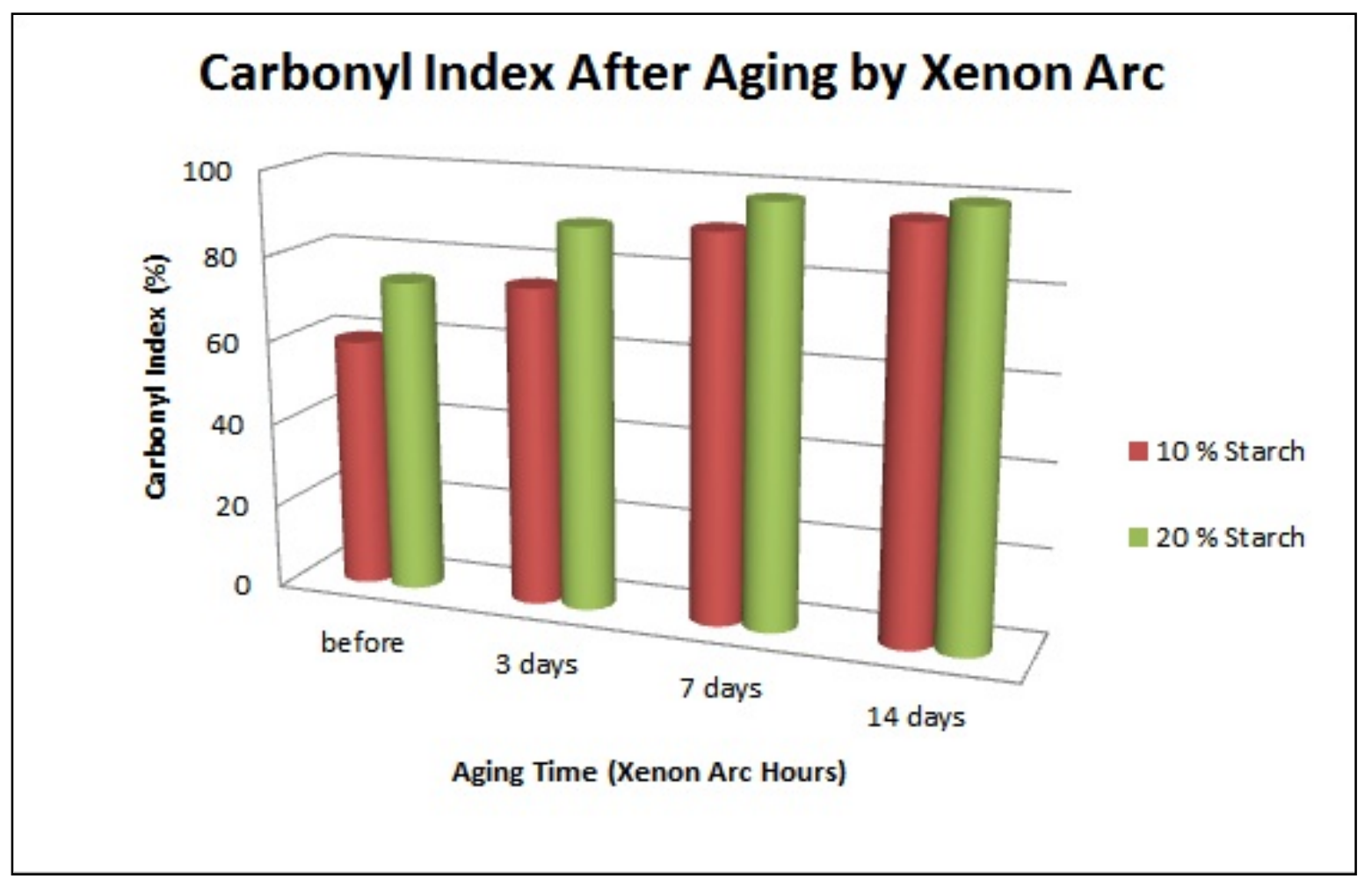

Figure 6. Carbonyl index for composite with $10 \mathrm{wt} \%$ and $20 \mathrm{wt} \%$ starch before and after been tested with Xenon Arc accelerated weathering.

\section{Conclusions}

Effects of Xenon Arc accelerated weathering treatment on LLDPE-starch-clay composite samples were analyzed using several techniques. In the mechanical test, tensile strength and the percent of elongation indicate a direct correlation with the exposure time of Xenon Arc test and starch content. FTIR analysis showed an increase in carbonyl index present on LLDPE-starch-clay composite after exposure to xenon arc. This fact indicated the 
degradation process suffered by the material especially on starch portion caused by exposure to Xenon Arc accelerated weathering.

\section{REFERENCES}

[1] U.S. EPA, MSW Generation, Recycling and Disposal in US, $1-12,2010$

[2] M.G.A. Vieira, M.A. da Silva, L.O. dos Santos, M.M. Beppu, Eur, Poly. J., , 47, 254-263, 2011

[3] N. Lucas, C. Bienaime, C. Belloy, M. Queneudec, F.
Silvestre, J. Nava-Saucedo, Chemosphere, 73, 429-442, 2008

[4] R. Bodirlau, L. Spiridon, C.A. Teaca, Mat. Plastice, 47, Nr.2, 2010

[5] Kaczmarek, H. \&Oldak, D. Polym. Degrad. Stab, 91,p.2282, 2006

[6] F.G.D. Fereirra, M.A.G.A. Lima, Y. M.B. Almeida, G.M., Vinhas, Polímeros: Ciência e Tecnologia19, No. 4, 313-317, 2009

[7] M. Avella, J. J. De Vlieger, M.E. Erico, S. Fischer, P. Vacca, M.G. Volpe, Food Chemistry, Vol 93, 467 - 474, 2005

[8] Sh. Khoramnejadian, H. Radnezhad, Bulgarian Chemical Communication, Vol 48, special issue D, 15 - 17, 2016 